\title{
TRIBOLOGICAL ASPECTS OF THE WALKING AND PRACTICAL DETERMINATION OF THE FRICTION COEFFICIENT USING A PORTABLE APPARATUS FOR GROUND REACTION FORCE ANALYSIS
}

\author{
PhD. Stud. Anghel Constantin ${ }^{1}$, Prof. DR. HC. PhD. Eng. Gheorghe I. Gheorghe ${ }^{2}$ \\ ${ }^{1}$ Doctoral School of Valahia University - Targoviste, Romania \\ ${ }^{2}$ National Institute of Research and Development in Mechatronics and Measurement Technique, \\ Bucharest, Romania \\ anghel.constantin@incdmtm.ro, incdmtm@incdmtm.ro
}

\begin{abstract}
In a framework within doctoral research study at the Valahia University from Targoviste and the National Institute for Research and Development for Mechatronics and Measurement Technique from Bucharest, with the aim to create a simple, reliable, mobile portable walking device, accessible both technical and financially, usable in natural walking conditions, and allowing to be obtained the objective and exploitable information to be found on the descriptive parameters of walking and energetic parameters, has created the idea of designing a tool to collect the information, of which the foot is capable to give during contact with the ground. If the measuring instrument could be in direct contact with the ground, then the main spatial-temporal parameters, the ground reaction forces and energy parameters could be analysed. Therefore, the need to propose a walking study based on the information and conclusions from the extensive documentation made previously appeared. If this tool could be placed in a footwear and be independent of any nearby analysis system, then it will be able to be used in natural walking conditions.

Among other facilities related to the complex analysis of ground forces, a dynamic variation form during a friction coefficient step could be determined and represented, a parameter that provides much information on walking pathology or shoe quality and footprint quality. Some significant aspects and results will be highlighted in this article.
\end{abstract}

Keywords: Walking analysis, Ground Reaction Force, Friction Coefficient, Tribology.

\section{Introduction}

The issue of considering tribological subjects as multidisciplinary is considered essential.

Definition: A system is a set of elements, interconnected by structures and functions [1].

Applying the general theory of systems implies the observance of two conditions: the interactions between the parts must be non-existent or at least small enough to be neglected. This condition leads to the fact that the parts can be isolated first, logically, mathematically and reassembled. Relationships that describe the influence of the parts must be linear, only this is the condition of additivity. For exemplification Figure 1 explain the system concept and the hierarchical principle for the tribological sensor assembly and the tire that applies to the footwear [2][3].

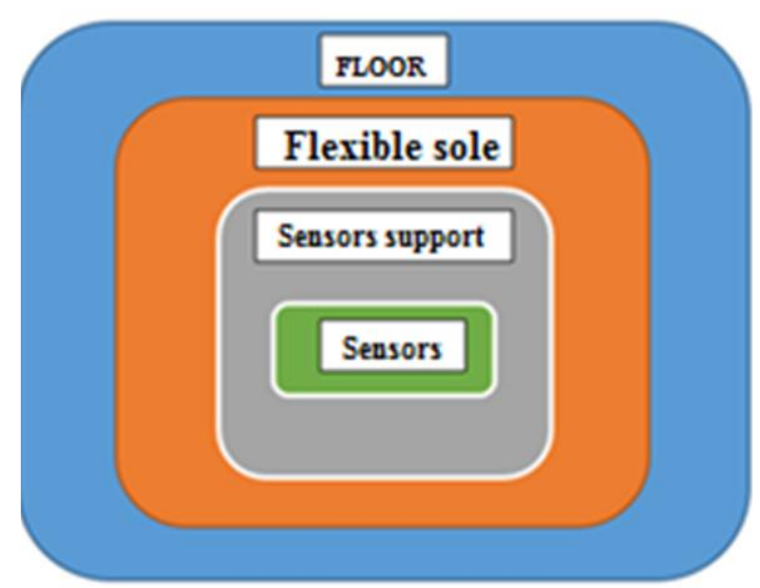

Figure 1- The diagram of tribological system formed by the sensor assembly 
Tribology is defined as the science of interaction of moving surfaces and as the study of the consequences resulting from this interaction

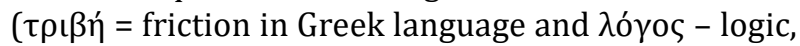
rationality, for the science term, in Greek language is used $\varepsilon \pi \iota \sigma \tau \mid \mu \eta=$ science).

The concept of tribology involves the interaction of two or more bodies, on one or more contact surfaces, with or without relative macroscopic movement, for the transmission of normal and tangential forces. Tangential forces that resist movement or movement tendency occur on contact surfaces. These forces are generally called friction forces.

At macroscopic level, the friction force is considered to be the result of the adhesion forces, the elastic and plastic deformation, and the electrostatic forces on the real contact surface represented simplified in Figure 2.

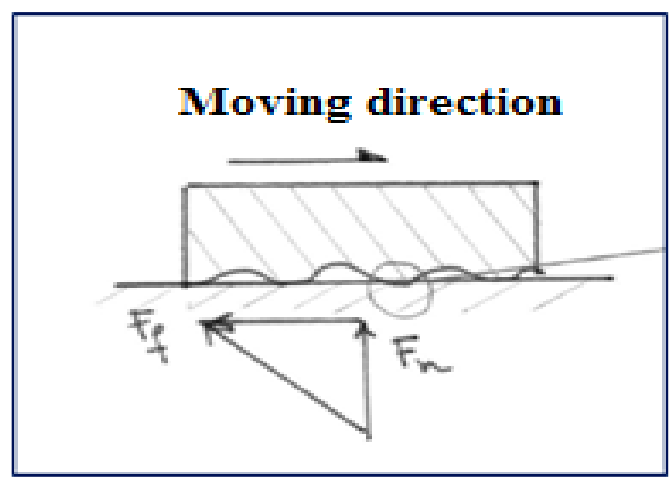

Figure 2: Conceptual simplified scheme

In the microscopic model of friction there are deformation processes and adhesion processes. Thus the kinetic coefficient of friction in dry regime is written as in relation (1):

$$
\mu=\frac{F_{E}}{F_{n}}
$$

In the tribology science it is considered that the mechanical work is a main parameter for the characterization of friction and wear phenomena.

The energy balance shows that the mechanical work at the entrance to the system is equal to the required mechanical work at the exit plus the energy stored in the system and the energy converted to thermal energy.

\section{Experimental work}

We recall that for the tribological system considered in Figure 1 the considered axle system is represented in Figure 3.

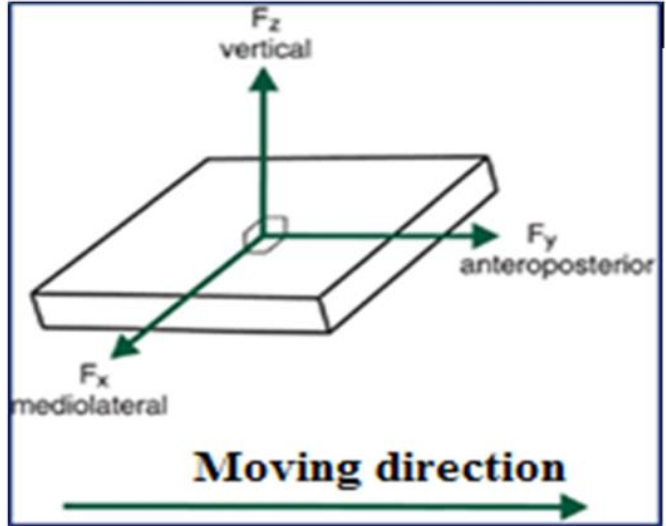

Figure 3: Reference axis system

Next we define the required coefficient of friction - RCOF as the minimum friction coefficient $\mu$, which must be available at the floor-to-floor interface to prevent slipping forward while walking.

In the literature, authors like Perkins [3] used a force platform to measure the horizontal (Fy) and vertical forces $(\mathrm{Fz})$, the forces exerted between the shoes and the ground during normal walking. The ratio of tangential forward and normal surface forces (Fy / Fz) is time-based function as in Figure no. 4.

Next we define the required coefficient of friction - RCOF as the minimum friction coefficient $\mu$, which must be available at the floor-to-floor interface to prevent slipping forward while walking [4][5].

In the literature [5] and other authors like Perkins used a force platform to measure horizontal (Fy) and vertical forces (Fz), the components of force exerted between shoes and the ground during normal walking. The ratio of tangential to forward and normal surface forces (Fy / Fz) is time-related function as in Figure 4 [3].

In the graph in Figure 4, the interesting points are numbered and have the following meanings:

$>1$ is the impact of the heel

$>2$ is the results of the force exerted as a reaction to the impact of the heel

$>3$ and 4 is the result of interaction with the floor and the beginning of the push

$>5$ and 6 is the detaching of the top of the floor.

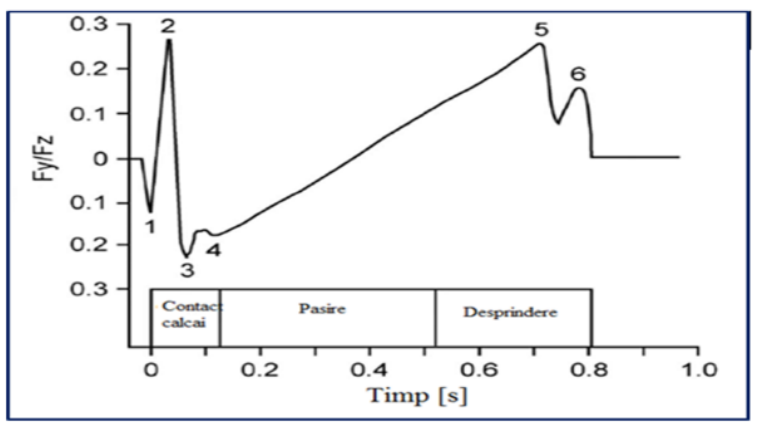

Figure 4: Friction coefficient diagram 
The ratio of the antero (shear force) and the vertical (normal) force generated during walking is also known as the friction coefficient (COF) during normal locomotion on dry surfaces.

The significance of the force ratio (Fy / Fz) is that it indicates, among other things, where the phase of a step would slip most likely [6].

The sliding most likely is in the braking phase of the FRS vertical, initially small at the moment of the heel impact, which produces a small amount of friction. If friction is not sufficient during the braking period, an ante-posterior foot slip will likely occur. This could be particularly dangerous due to the presence of rapid energy transfer to one of the legs during the fall.

Recent discoveries about human walking biomechanics have highlighted the ability to adapt to slippery "potential" surfaces. Such studies have been performed on subjects who have walked on a known dry (traction) surface [5]

The overall effect of these adaptations was a reduction in the minimum required peak COF (Redfern and DiPasquale 1997), therefore, humans have the ability to reduce the slip potential with regard to the interaction of footwear with the floor (Cham and Redfern 2002) [7].

Measurements to highlight minimal tribological aspects such as friction coefficients were also performed using the CALORCRO system in its own construction based on the mentioned sensor system.

Considering the axis system of Figure 3, the reaction forces will decompose as in Figure 5.

A standardized procedure to be applied to such measurements is included in the International Standard on Shoe Slip Resistance Assessment ISO 13287: 2006; Personal Protective Equipment Footwear - Test Method for Slip Resistance.

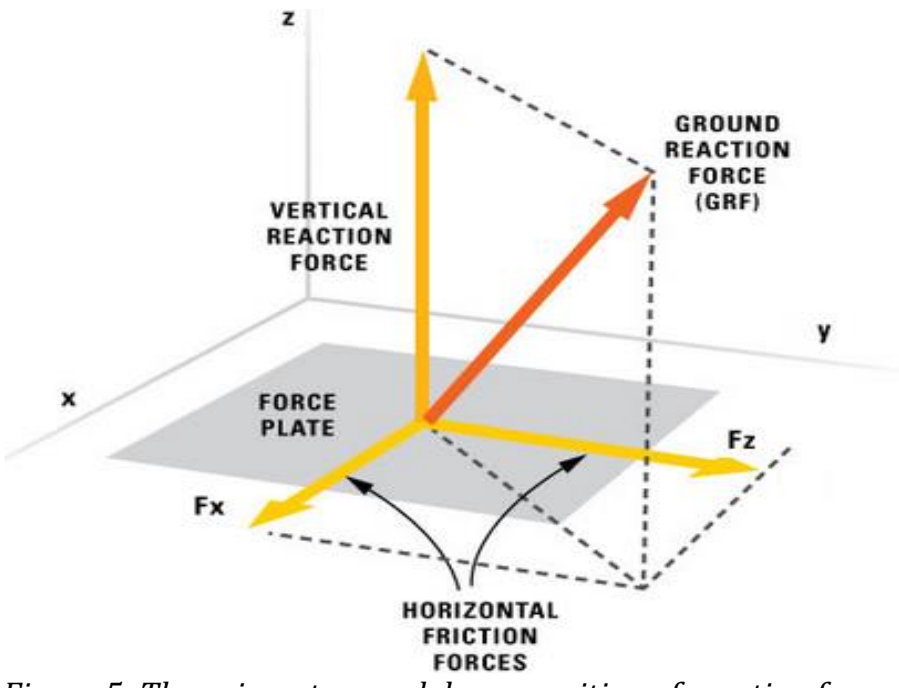

Figure 5: The axis system and decomposition of reaction forces

The procedure used is also based on the fact that the realized system uses a calibration method for each sensor by controlled load with a force up to $1000 \mathrm{~N}$, the procedure described in a separate chapter.

Such a procedure allows for a more accurate COF footprint calculation because the body weight of the subject in real-time is determined simultaneously with the FRS collected while the subject travels a distance of $10 \mathrm{~m}$, going normally. Thus, the ratio between $\mathrm{Fy}$ and $\mathrm{Fz}$ determined the time variation of the dynamic (kinetic) COF coefficient of friction.
The results for determining the Fy / Fz tribological ratio were obtained as an additional requirement to the initial purpose of the project at the suggestion of the guidance committee [8].

The measured and calculated values are shown in Table 1 and based on these values, Figure 6 is graphically depicted in the same diagram the FRS evolution and the Fy / Fz ratio for one step.

The measured values calculate the finding of the presentation in Table 1 and based on these values in Figure 6 is plotted in the same FRS evolution chart and a Fy / Fz ratio for one step. 
Tribological Aspects of the Walking and Practical Determination of the Friction Coefficient Using a Portable Apparatus for Ground Reaction Force Analysis

\begin{tabular}{|c|c|c|c|c|c|c|c|c|c|c|c|c|c|c|c|c|c|c|c|c|}
\hline \multirow{2}{*}{\multicolumn{2}{|c|}{ CAZACIOC: }} & \multicolumn{2}{|c|}{$\mathrm{m}=42.894 \mathrm{Kg}$} & \multicolumn{2}{|c|}{$\mathrm{L}=0,900[\mathrm{~m}]$} & \multicolumn{2}{|c|}{$\mathrm{G}=420,8 \mathrm{~N}$} & & & & & & & & \multirow{2}{*}{\begin{tabular}{|l|}
$y m e d:$ \\
0.1312
\end{tabular}} & \multirow{2}{*}{\begin{tabular}{|l|}
$d y:$ \\
0.1027 \\
\end{tabular}} & \multirow{2}{*}{$\begin{array}{ll}\text { h: } \\
0.0422 \\
\end{array}$} & \multirow{2}{*}{$\begin{array}{l}\mathrm{r}: \\
0.4041\end{array}$} & \multirow{2}{*}{ L: } & \multirow[t]{2}{*}{ 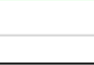 } \\
\hline & & (pas 3) & & & & & & & & & & & & & & & & & & \\
\hline \multicolumn{3}{|c|}{$\begin{array}{r}\text { faza de sprijin (pas } 3 \text { ) } \\
\text { valori măsurate }\end{array}$} & & & & & & & & \multicolumn{5}{|c|}{ valori calculate } & & & & & & \\
\hline$t[s]$ & $f_{s i}$ & fdi & $\mathrm{yi}[\mathrm{mm}]$ & fzi & azi & azdi & dvzi & \multicolumn{2}{|c|}{ calcul v0 } & vzi & dhi & hi & $\mathbf{L}$ & $r$ & ymed & $\theta \mathrm{i}$ & fyi & vyi & vayi & pyi \\
\hline 63.98 & 446.71 & 34.69 & 28.48 & 481.40 & 1.41 & 0.102 & 0.002 & 1 & 0.002 & 0.556 & 0.0111 & 0.0111 & 0.90 & 0.404 & \begin{tabular}{|l|}
0.1312 \\
\end{tabular} & -0.2571 & -9.120 & -0.370 & -1.194 & 10.89 \\
\hline 64.00 & 302.91 & 462.01 & 21.08 & 764.92 & 8.02 & 4.846 & 0.097 & 2 & 0.194 & 0.554 & 0.0111 & 0.0222 & 0.90 & 0.404 & 0.1312 & -0.2761 & -130.890 & 0.227 & 0.733 & -95.89 \\
\hline $\begin{array}{ll}64.02 \\
\end{array}$ & 129.17 & 557.91 & 25.62 & 687.08 & 6.21 & 5.041 & 0.101 & 3 & 0.302 & 0.457 & 0.0091 & 0.0314 & 0.90 & 0.404 & 0.1312 & -0.2644 & -151.055 & 163 & .526 & -79.46 \\
\hline 64.04 & 21.608 & 562.28 & 28.88 & 583.89 & 3.80 & 3.662 & 0.073 & 4 & 0.293 & 0.357 & 71 & 85 & 0.90 & 0.404 & 0.1312 & -0.2561 & -147.211 & 696 & 2.245 & 330.42 \\
\hline 64.06 & 0 & 652.758 & 42.79 & 652.76 & 5.41 & 5.408 & 0.108 & 5 & 0.541 & 0.283 & & 42 & 0.90 & 0.404 & \begin{tabular}{|l|}
0.1312 \\
\end{tabular} & -0.2206 & -146.406 & .574 & 1.851 & 0.97 \\
\hline 64.08 & 0 & \begin{tabular}{|l|l|}
622.148 \\
\end{tabular} & 54.26 & 622.15 & 4.69 & 4.694 & 0.094 & 6 & 0.563 & 0.175 & & 77 & 0.90 & 0.404 & 0.1312 & -0.1916 & \begin{tabular}{|l|}
-120.708 \\
\end{tabular} & .577 & .862 & 4.77 \\
\hline 64.10 & 0 & \begin{tabular}{|l|}
618.063 \\
\end{tabular} & 5.8 & .06 & 4.60 & 599 & 0.092 & 7 & 0.644 & 0.081 & 16 & 93 & 0.90 & 0.404 & 0.1312 & -0. & -101.407 & 0.720 & 2.322 & 5.47 \\
\hline 64.12 & 0 & \begin{tabular}{|l}
569.255 \\
\end{tabular} & 80.19 & 569.26 & 3.46 & 3.461 & 0.069 & 8 & 0.554 & -0.011 & 02 & 91 & 0.90 & 0.404 & 0.1312 & -0.1266 & -72.476 & 796 & 2.567 & -186.06 \\
\hline 64.14 & 0 & 517.653 & 96.1 & 517.65 & 2.26 & 2.258 & 0.045 & 9 & 0.406 & -0.080 & -0.0016 & 0.0475 & 0.90 & 0.404 & 0.1312 & -0.0870 & -45.168 & 0.803 & 2.590 & -116.98 \\
\hline 64.16 & 0 & \begin{tabular}{|l}
45.328 \\
\end{tabular} & 112.15 & 454.33 & 0.78 & 0.782 & 0.016 & 10 & 0.156 & -0.125 & -0.0025 & 0.0450 & 0.90 & 0.404 & \begin{tabular}{|l|}
0.1312 \\
\end{tabular} & -0.0472 & -21.471 & 0.855 & 2.761 & -59.28 \\
\hline 64.1 & 0 & & & & - & & & 11 & & & & & 90 & 04 & 12 & 49 & 40 & 34 & 92 & 22 \\
\hline 64.20 & 0 & \begin{tabular}{|l|}
360.325 \\
\end{tabular} & 5.94 & 360.33 & -1.41 & - & -0.028 & 12 & -0.338 & -0.131 & & 95 & 0.90 & 0.404 & 0.1312 & 0.0364 & 13.130 & .024 & 3.303 & 3.37 \\
\hline 64.22 & 0 & \begin{tabular}{|l|}
317.617 \\
\end{tabular} & 166.41 & 317.62 & -2.41 & -2.405 & -0.048 & 13 & -0.625 & -0.102 & & 0. & 0.90 & 0.404 & 0.1312 & 0.0872 & 27.761 & .633 & 2.043 & 56.71 \\
\hline 64.24 & 0 & \begin{tabular}{|l|}
313.872 \\
\end{tabular} & 179.07 & 313.87 & -2.49 & -2.493 & -0.050 & 14 & -0.698 & -0.054 & -0 . & 0.0364 & 0.90 & 0.404 & 0.1312 & 87 & 37.427 & 0.197 & 0.636 & 23.79 \\
\hline 64.26 & 0 & \begin{tabular}{|l|}
322.735 \\
\end{tabular} & 183.01 & 322.74 & -2.29 & -2.286 & -0.046 & 15 & -0.686 & -0.004 & -0.0 & 0.0363 & 0.90 & 0.404 & 0.1312 & 0.1285 & 41.703 & 0.063 & 0.203 & 8.48 \\
\hline 64.28 & 0 & 339.73 & 184.27 & \begin{tabular}{|l|}
339.73 \\
\end{tabular} & -1.89 & -1.890 & -0.038 & 16 & -0.605 & 0.041 & 0.00 & 0.0372 & 0.90 & 0.404 & 0.1312 & 0.1317 & 44.986 & 0.160 & 0.518 & 23.30 \\
\hline 64.30 & 0 & 355.43 & 187.48 & 355.43 & -1.52 & -1.524 & -0.030 & 17 & -0.518 & 0.079 & 0.0016 & 0.0387 & 0.90 & 0.404 & 0.1312 & 0.1397 & 49.968 & 0.209 & 0.674 & 33.70 \\
\hline 64.32 & 0 & \begin{tabular}{|l|l|}
403.652 \\
\end{tabular} & 191.66 & \begin{tabular}{|l|}
403.65 \\
\end{tabular} & -0.40 & -0.400 & -0.008 & 18 & -0.144 & 0.110 & 0.0022 & 0.0409 & 0.90 & 0.404 & \begin{tabular}{|l|}
0.1312 \\
\end{tabular} & 0.1501 & 61.057 & 0.163 & 0.526 & 32.12 \\
\hline 64.34 & 0 & \begin{tabular}{|l|}
443.283 \\
\end{tabular} & 194.92 & 443.28 & 0.52 & 0.524 & 0.010 & 19 & 0.199 & 0.118 & 0.0024 & 0.0433 & 0.90 & 0.404 & 0.1312 & 0.1583 & 70.758 & 0.178 & 0.574 & 40.65 \\
\hline 64.36 & 0 & 494.66 & 198.48 & 494.66 & 1.72 & 1.722 & 0.034 & 20 & 0.689 & 0.107 & 0.0021 & 0.0454 & 0.90 & 0.404 & \begin{tabular}{|l|}
0.1312 \\
\end{tabular} & 0.1672 & 83.494 & 0.158 & 0.508 & 42.44 \\
\hline 64.38 & 0 & 539.62 & 201.63 & \begin{tabular}{|l|}
539.62 \\
\end{tabular} & 2.77 & 2.770 & 0.055 & 21 & 1.164 & 0.073 & 0.0015 & 0.0469 & 0.90 & 0.404 & \begin{tabular}{|l|l|}
0.1312 \\
\end{tabular} & 0.1751 & 95.480 & 0.124 & 0.399 & 38.05 \\
\hline 64.40 & 0 & \begin{tabular}{|l|}
577.037 \\
\end{tabular} & 204.1 & \begin{tabular}{|l|}
577.04 \\
\end{tabular} & 3.64 & 3.643 & 0.073 & 22 & 1.603 & 0.017 & 0.0003 & 0.0472 & 0.90 & 0.404 & \begin{tabular}{|l|}
0.1312 \\
\end{tabular} & 0.1813 & 105.800 & 0.142 & 0.457 & 48.31 \\
\hline 64.42 & 0 & 594.79 & 206.93 & 594.79 & 4.06 & 4.057 & 0.081 & 23 & 1.866 & -0.056 & -0.0011 & 0.0461 & 0.90 & 0.404 & 0.1312 & 0.1885 & 113.441 & 0.169 & 0.544 & 61.69 \\
\hline 64.44 & 0 & 587.997 & 210.3 & 588.00 & 3.90 & 3.898 & 0.078 & 24 & 1.871 & -0.137 & -0.0027 & 0.0434 & 0.90 & 0.404 & 0.1312 & 0.1970 & 117.332 & 0.140 & 0.450 & 52.82 \\
\hline 64.46 & 0 & \begin{tabular}{|l|}
561.388 \\
\end{tabular} & 213.09 & 561.39 & 3.28 & 3.278 & 0.066 & 25 & 1.639 & -0.215 & -0.0043 & \begin{tabular}{|l|}
0.0391 \\
\end{tabular} & 0.90 & 0.404 & \begin{tabular}{|l|l|}
0.1312 \\
\end{tabular} & 0.2040 & 116.141 & 0.240 & 0.775 & 89.96 \\
\hline 64.48 & 121.03 & 471.89 & 217.89 & \begin{tabular}{|l|}
592.92 \\
\end{tabular} & 4.01 & 3.194 & 0.064 & 26 & 1.661 & -0.280 & -0.0056 & \begin{tabular}{|l|}
0.0335 \\
\end{tabular} & 0.90 & 0.404 & 0.1312 & 0.2162 & 103.618 & 0.326 & 1.050 & 108.85 \\
\hline 64.50 & 423.29 & \begin{tabular}{|l|l|}
338.228 \\
\end{tabular} & 224.4 & \begin{tabular}{|l|}
761.52 \\
\end{tabular} & 7.94 & 3.528 & 0.071 & 27 & 1.905 & -0.344 & -0.0069 & 0.0266 & 0.90 & 0.404 & 0.1312 & 0.2327 & 80.149 & 0.338 & 1.089 & 87.30 \\
\hline 64.52 & 560.62 & \begin{tabular}{|l|}
188.477 \\
\end{tabular} & 231.15 & 749.10 & 7.65 & 1.926 & 0.039 & 28 & 1.078 & -0.415 & -0.0083 & \begin{tabular}{|l|l}
0.0183 \\
\end{tabular} & 0.90 & 0.404 & 0.1312 & 0.2499 & 48.102 & 0.141 & 0.455 & 21.89 \\
\hline \multirow[t]{2}{*}{64.54} & 546.14 & 62.625 & 233.97 & \begin{tabular}{|l|}
608.77 \\
\end{tabular} & 4.38 & 0.451 & 0.009 & 29 & 0.261 & -0.453 & -0.0091 & 0.0092 & 0.90 & 0.404 & 0.1312 & 0.2571 & 16.464 & & & \\
\hline & & & & & & & & & v0: & -0.462 & 0.0000 & & & & & & & & Py: & 0.0 \\
\hline
\end{tabular}

The electronic equipment developed in the doctoral research is portable, it applies a new method of assessing the energy consumption on walking, using a calculation algorithm based on the measurement of the vertical reaction force on the ground and on the determination of the coordinates of its application point.

The equipment will consist of two power sensors (for right foot and left foot), two electronic blocks conditioning signal, a microcontroller data acquisition system, and specialized software.
The two resistors provided with resistive tactile sensors measure the vertical ground reaction force at 8 foot-to-ground contact points.

The signals provided by force resistive tactile sensors are amplified and digitized by the conditioning blocks, attached to the back of the shoe of the subject under consideration.

Signal conditioning blocks are connected to the data acquisition unit, fixed on a strap attached to the middle of the subject under consideration as we can see in Figure 7

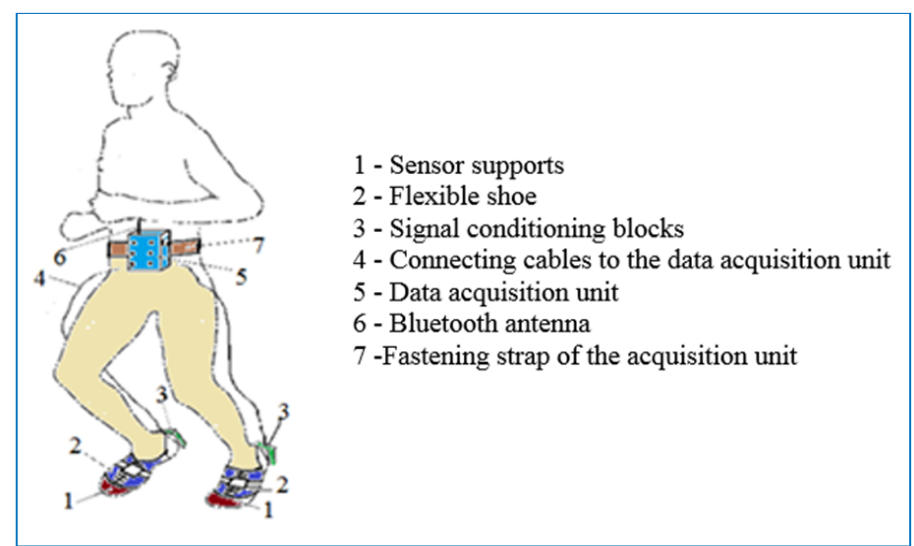

Figure 7: Portable electronic equipment for gait analysis and determination of calorimetry when walking

The experimental results from table 1 are the basis of the calculation of the Fy/Fz ratio, graphically represented in Figure 8 with the highlighting of sliding risk moments. 


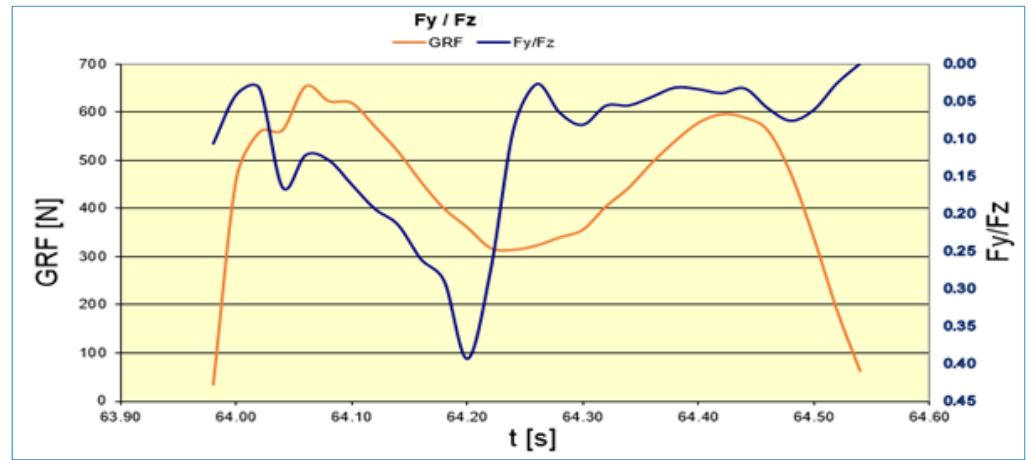

Figure 8: The graph obtained from the table no. 1

\section{Conclusions on Tribological Analysis}

Experimental results indicate interesting research directions to determine the risk of slipping or even dropping depending on different flooring materials (the equipment applied over the shoes is the same). The main risk factor for slippage is, by definition, the reduced friction between shoe and walking surface [9][10].

$>$ Determination of the degree of wear of the flexible soles and of the sensor system

$>$ Determination of the pattern correlated with various diseases like diabetes and Parkinson's disease.

$>$ Determination of the pattern correlated with various surgical interventions and prosthesis

The importance of tribological study of the system:

$>$ The wear study

$>$ The study of fatigue

$>$ The study of slippage

$>$ The study of footwear's influence and floor interface by walking.

\section{References}

[1] Anghel CONSTANTIN, Gheorghe I. GHEORGHE, CMOS transducer with linear response using negative capacitance for the force measurement in human walking analysis with applications in MEMS and NEMS technologies", Springer Lecture Notes on Electrical Engineering, SSN: 18761100Chang, W.R., Gronqvist, R., Leclercq, S., Brungraber, R.J., Mattke, U., Strandberg, L., Thorpe, S.C., Myung, R., Makkonen, L. and Courtney, T.K.,The role of friction in the measurement of slipperiness, Part 2: survey of friction measurement devices. Ergonomics, 2001, Vol. 44, pp.1233-1261
[2] Gheorghe I. Gheorghe, Mecatronica \& Sistemele Cyber - Mecatronice, ISBN 978-606-8261-22-5, Ed. CEFIN, 2015, pp. 236-237;

[3] Chang, W.R., Gronqvist, R., Leclercq, S., Brungraber, R.J., Mattke, U., Strandberg, L., Thorpe, S.C., Myung, R., Makkonen, L. and Courtney, T.K.,The role of friction in the measurement of slipperiness, Part 2: survey of friction measurement devices. Ergonomics, 2001, Vol. 44, pp.1233-1261

[4] Perkins, P.J.,"Measurement of slip between the shoe and ground during walking. In: C. Anderson and J. Senne, eds. Walkway surfaces: Measurement of slip resistance". Baltimore, MD: American Society for Testing and Materials, 1978, pp. 71-87.

[5] Machado, Jose; Soares, Filomena; Leao, Celina P. , A Virtual Workbench Applied to Automation: Student's Response Analysis, Controlo'2014 Proceedings, of the 11th, Portuguese Conference on Automatic Control Volume:321 Pages: 709719, Published: 2015.

[6] Bentley and Haslam 2001, Chang and colab.2001a, b, Gronqvist and colab. 2001b, Haslam and Stubbs 2006)

[7] Moyer, B.E., Chambers, A.J., Redfern, M.S., and Cham, R., 2006. Gait parameters as predictors of slip severity in younger and older adults. Ergonomics, 49, pp. 329-343.

[8] Rizescu, C.I., Udrea, C. Rizescu, D.,Experimental Setup for Harmonic Drive Efficiency Determination, Advanced Materials Research Vols. 463-464 (2012) pp. 1518-1521

[9] Gheorghe I. Gheorghe, Liliana-Laura Badita, "Improving Tribological Characteristics of Hip Prosthesses Using Biocompatible Nanocoatings", Advanced Materials Research, Vol. 741 (2013); pp. 67

[10]Rochdi El Abdi, Erwann Carvou. Damage Study of Copper Alloys Submitted to Vibration Tests The ASME 2010 International Design Engineering Technical Conferences (IDETC) and Computers and Information in Engineering Conference (CIE), Aug 2010, Montreal, Canada. pp. 747-752, 2010. 